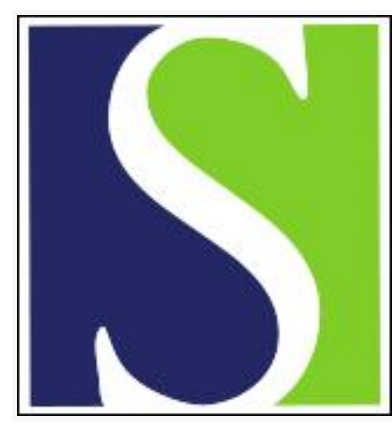

Scand J Work Environ Health 1993;19(2):121-125

https://doi.org/10.5271/sjweh.1497

Issue date: 01 Apr 1993

Psychological distress and alcohol use among fire fighters.

by Boxer PA, Wild D

Affiliation: Division of Surveillance, Hazard Evaluations, and Field Studies, National Institute for Occupational Safety and Health, Cincinnati, Ohio 45226.

This article in PubMed: www.ncbi.nlm.nih.gov/pubmed/8316779

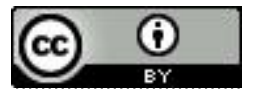




\title{
Psychological distress and alcohol use among fire fighters
}

\author{
by Peter A Boxer, MD, Deanna Wild, MS'
}

\begin{abstract}
BOXER PA, WILD D. Psychological distress and alcohol use among fire fighters. Scand J Work Environ Health 1993;19:121 -5. Few studies have investigated stressors to which fire fighters are subjected and the potential psychological consequences. One hundred and forty-five fire fighters were studied to enumerate potential occupational stressors, assess psychological distress and problems with alcohol use, and determine whether a relationship exists between these measures and self-reported stressors. Hearing that children are in a burning building was the highest ranked stressor. According to three self-report instruments, between 33 and $41 \%$ of the fire fighters were experiencing significant psychological distress, and $29 \%$ had possible or probable problems with alcohol use. These figures are significantly higher than would be expected in a typical community or working population. In a logistic regression analysis, no relationship was found between measures of psychological distress and alcohol use and the 10 most highly ranked work stressors.
\end{abstract}

Key terms: alcoholism, depression, work stress.

According to a 1985 study conducted by the International Society of Fire Service Instructors, an estimated 242000 professionals and 919000 volunteers work in the United States as fire fighters (personal communication, Learning Resource Center of $\mathrm{Na}-$ tional Fire Academy, Emmitsburg, Maryland). The Jobs Rated Almanac (1) ranks fire fighters as having the most stressful job in the United States. Potential stressors to which fire fighters are exposed range from threat of bodily harm while fighting fires to boredom while waiting to be summoned. In addition, occupational health investigators are becoming increasingly aware of possible long-term health hazards of fire fighting. For example, combustion of synthetic material can produce gases which can potentially cause cancer or liver or kidney toxicity (2).

Several studies have examined the physiological responses of fire fighters to alarms, fire fighting, or near-maximal exercise (3-5). Average heart rates as high as 188 beats per minute have been recorded during fire fighting (3). Studies examining the role of psychological factors in the etiology of elevated heart rates in response to alarm have yielded conflicting results (3-5). Emotional stress has been considered a possible factor explaining the unusually high incidence of ischemic stress tests found in a study of fire fighters in Los Angeles, California (6).

No common themes emerge from a review of the few studies which have employed widely divergent methods to look at the relationship between psycho-

1 Division of Surveillance, Hazard Evaluations, and Field Studies, National Institute for Occupational Safety and Health, Cincinnati, Ohio, United States.

Reprint requests to: Dr PA Boxer, DSHEFS, MS R41, National Institute for Occupational Safety and Health, 4676 Columbia Parkway, Cincinnati, OH 45226, USA. logical stress and stress-related symptoms in fire fighters. Over $30 \%$ of the fire fighters and paramedics surveyed by Dutton et al (7) scored above 150 "life change units," a possible predictor of susceptibility to future illness. Paramedics reported a somewhat higher level of stress than did fire fighters. Petrie \& Rotheram's (8) survey of 106 fire fighters showed that high self-esteem and high assertiveness were associated with low levels of stress. Clarke \& Innes (9), studying Australian fire fighters, found that fire fighters high in "sensation-seeking motivation" (needing varied and complex sensations and experiences) showed a stronger relationship between life events and illness than did those with low sensationseeking motivation. Bieliauskas (10) found no relationship between stressful life events, cortisol levels, and "psychological defensiveness" in the seeking of medical or psychological aid among 80 fire fighters. In the largest published study, Kalimo (11) found that job satisfaction among 260 Finnish fire fighters was high, and the prevalence of psychological symptoms was lower than that of the Finnish population. Markowitz (12), studying 64 fire fighters who had fought a large polyvinyl chloride fire, found high levels of demoralization and emotional distress 22 months after the incident.

In 1985, the National Institute for Occupational Safety and Health initiated a study of occupational stress among fire fighters at the request of the International Association of Fire Fighters (IAFF). A preliminary questionnaire was completed by 41 fire fighters and fire fighting officers who attended an IAFF symposium in Houston, Texas, in September 1985. In August 1986, the Cincinnati, Ohio, Fire Division and Cincinnati fire fighters Union Local 48 (IAFF) supported a larger study, using a revised 317 -item questionnaire taking approximately $90 \mathrm{~min}$ 
to complete, among Cincinnati fire fighters. The objectives of this study were to enumerate potential workplace stressors, to assess psychological distress and problems with alcohol use, and to determine whether a relationship exists between the levels of the stressors and measures of psychological distress and alcohol use. At the time of the study, the Cincinnati Fire Department employed 769 fire fighters. After reviewing the statistics of the annual report of the Fire Department, we chose eight fire houses representing a spectrum of level of work activity to join the study. Of the 147 fire fighters in these houses, 145 agreed to participate.

\section{Subjects and methods}

A list of 72 potential workplace stressors was developed from the published literature (3-13), feedback from the questionnaires completed in Houston, and interviews with 10 Cincinnati fire fighters. These stressors were grouped into 10 categories based on the type of job stress (eg, potential toxic exposures, relationship between workers and supervisors, problems with the work, and family-home interface). The objective measures of work stressors consisted of the number of runs during the previous year and the number of hours fighting fires during the previous year.

As measures of psychological distress and alcohol use, we employed validated instruments which permit comparison with published norms. The Symptom Check List (SCL 90-R) consists of 90 items which include the following nine primary symptom dimensions: somatization, obsessive-compulsive, interpersonal sensitivity, depression, anxiety, hostility, phobic anxiety, paranoid ideation, and psychoticism (14). The Global Severity Index (GSI) of the SCL-90-R is a summary measure of symptoms reported and level of distress. The General Health Questionnaire (GHQ), a screening instrument for assessing mental health, has been widely used in epidemiologic studies $(15,16)$. The form utilized in this study, consisting of 12 items, was used in a study of the mental health of office workers in Hong Kong (17). The Center for Epidemiologic Studies Depression Scale (CES-D) was developed by the National Institute of Mental Health to measure depressive symptomatology in the general population (18). The aspects of depression measured include feelings of guilt, worthlessness, helplessness and hopelessness, loss of appetite, sleep disturbance, and psychomotor retardation. The CES-D has been found to have high reliability and validity among a variety of general population samples. The Michigan Alcoholism Screening Test (MAST) is a structured self-administered instrument generally considered to be a reliable tool for screening for alcoholism $(19,20)$.

Using the hypothesis that the level of work stressors (independent variables) would be predictive of measures of psychological distress and alcohol use (dependent variables), we performed a logistic regression analysis (SAS Version 6.04, Statistical Analysis System, Cary, North Carolina). Potential confounding variables consisted of age, race, level of education, measures of social support, marital status, hours of outside employment, years of employment, and personality and environment "domains" of the Derogatis Stress Profile (DSP) $(21,22)$. The DSP is a multidimensional stress profile, consisting of 77 items. The environment domain measures potential stress-inducing events in the home, work, and health environments, while the personality domain measures personality characteristics of reaction to time-induced pressure, driven behavior, attitude posture (achievement orientation), relaxation potential, and role definition. Because our primary interest was to examine potentially clinically significant levels of psychological distress and alcohol use, scores for the dependent variables were dichotomized according to published recommended guidelines $(14,15,18,19)$. A case was defined as a score of at least 0.56 on the GSI of the SCL-90-R (T score $\geq 63$ ), 2 on the GHQ, 21 on the CES-D (moderate to severe depression), or 4 on the MAST (possible or probable problem with alcohol use).

\section{Results}

Of the 145 male fire department employees surveyed, $107(76 \%)$ were white. Their mean age was 38.7 (range 21-58) years, and their mean length of employment with the fire department was 13.8 (range 1-34) years. The level of schooling ranged from 9 to 17 years. Only two fire fighters $(1 \%)$ had less than a high school education, and $68(48 \%)$ had continued their education beyond high school. With regard to marital status, $75 \%$ were married, $12 \%$ had never married, and $13 \%$ were separated or divorced. Most of the employees surveyed performed multiple job activities, the most frequent being fire fighter $(77 \%)$ and emergency medical technician (69\%). Eightyfour $(58 \%)$ of the fire fighters had additional parttime jobs, averaging $21 \mathrm{~h}$ weekly.

The 10 highest ranked work stressors are listed in table 1 . The highest ranked stressor was "hearing that children are in a burning building," which received an average score of 2.86 out of a possible 4 . The three measures of psychological distress utilized were the GHQ, SCL-90-R, and CES-D. On the GHQ, 56 (39\%) of the 145 fire fighters scored two or higher, suggestive of a high level of emotional distress. Scores on the SCL-90-R were compared with norms based on test results of 482 male nonpatients. For the 145 fire fighters surveyed, the average GSI score was 0.58 , a score expected to be exceeded by only $10 \%$ of a "normal" population. Fifty-nine $(41 \%)$ of the 145 fire fighters had a GSI score above what is generally considered the "normal" range (above 90th percentile). The CES-D scores were compared with 
Table 1. Ten highest ranked stressors reported by 145 fire fighters.

\begin{tabular}{|c|c|c|}
\hline & Stressor & $\begin{array}{c}\text { Degree of } \\
\text { stress }^{a}\end{array}$ \\
\hline 1. & $\begin{array}{l}\text { Hearing that children are in a burning } \\
\text { building }\end{array}$ & 2.86 \\
\hline 2. & $\begin{array}{l}\text { Being concerned about possible exposure } \\
\text { to unknown toxic substances }\end{array}$ & 2.58 \\
\hline 3. & $\begin{array}{l}\text { Being concerned about exposure to persons } \\
\text { who have acquired immunodeficiency } \\
\text { syndrome (AIDS), hepatitis, tuberculosis, } \\
\text { or other infectious diseases }\end{array}$ & 2.57 \\
\hline 4. & $\begin{array}{l}\text { Believing that reverse prejudice exists } \\
\text { towards nonminority groups }\end{array}$ & 2.56 \\
\hline 5. & Being disturbed by tone or intensity of belis & 2.55 \\
\hline 6. & Feeling responsible for other people's lives & 2.55 \\
\hline 7. & $\begin{array}{l}\text { Feeling a lack of support from city } \\
\text { government }\end{array}$ & 2.54 \\
\hline 8. & $\begin{array}{l}\text { Feeling that the public has the wrong idea of } \\
\text { what firefighting work involves }\end{array}$ & 2.18 \\
\hline 9. & $\begin{array}{l}\text { Feeling that there is insufficient manpower } \\
\text { to deal with the workload }\end{array}$ & 2.15 \\
\hline 10. & $\begin{array}{l}\text { Feeling overutilized for emergency medical } \\
\text { service runs for nonemergency purposes }\end{array}$ & 2.08 \\
\hline
\end{tabular}

a Measured on a scale of 0 (not at all stressful) to 4 (extremely stressful).

those of approximately 3000 respondents to the Health and Nutrition Examination Survey conducted in 1974-1975. A score of less than 16 is considered "normal," 16-20 suggests a level of depression or emotional distress of a mild nature, $21-30$ suggests a moderate degree of depression or emotional distress, and a score of greater than 30 suggests a severe level of depression or emotional distress. The mean score was 12.96 , and $48(33 \%)$ of the 145 fire fighters achieved scores of 16 or higher, as presented in table 2.

A diagnosis of alcoholism cannot be made by questionnaire alone. Nevertheless, MAST provides a good estimate of the likelihood of current problems with alcohol use. Forty-two (29\%) of the 145 fire fighters had scores suggestive of possible or probable current problems with alcohol use, as outlined in table 2.

Table 3 presents the odds ratios (OR) and associated $95 \%$ confidence intervals for the variables entered into the logistic regression model. The majority of these statistically significant $O R$ values appear to be small. However, OR values which look relatively low are not trivial if the independent variable is continuous. The most striking finding was the indication of an increased risk of emotional distress for those individuals involved in stressful worker-supervisor relationships. This result is evidenced by the OR of 7.3 for the "relationship between workers and supervisors" variable in a model with CES-D as the dependent variable and other independent variables as specified in the Methods section. As an illustration, an OR of 7.3 in this case indicates that an in-
Table 2. Depression (CES-D) ${ }^{\mathrm{a}}$ and alcohol use (MAST) ${ }^{\mathrm{b}}$ scores for 145 firefighters.

\begin{tabular}{lcr}
\hline & Frequency & Percent \\
\cline { 2 - 3 } CES-D score & & \\
$0-15$ & 97 & 66.9 \\
$16-20$ & 19 & 13.1 \\
$21-30$ & 22 & 15.2 \\
$>30$ & 7 & 4.8 \\
MAST score & & \\
$0-3$ & 86 & 59.3 \\
4 & 10 & 6.9 \\
Nondrinker & 32 & 22.1 \\
Non & 17 & 11.7 \\
\hline
\end{tabular}

a Center for Epidemiologic Studies Depression Scale.

b Michigan Alcoholism Screening Test.

Table 3. Odds ratios (OR) and associated $95 \%$ confidence in tervals $(95 \% \mathrm{Cl})$ for the independent variables entered into the logistic regression model according to the dependent variables with which they were entered.

\begin{tabular}{lcc}
\hline Dependent variable & OR & $95 \% \mathrm{Cl}$ \\
\hline $\begin{array}{l}\text { Alcohol use (MAST) } \\
\text { Environment domain }\end{array}$ & & \\
$\begin{array}{l}\text { Depression (CES-D) } \\
\text { b }\end{array}$ & 1.03 & $1.00-1.05$ \\
$\quad$ Relationship between workers and & & \\
supervisors & & \\
Years of employment & 7.27 & $2.51-21.10$ \\
Environment domain & 0.66 & $0.48-0.90$ \\
Hours at fires & 1.05 & $1.02-1.09$ \\
GHQc & 0.99 & $0.98-1.00$ \\
Personality domain & & \\
Environment domain & 1.02 & $1.01-1.05$ \\
GSI (SCL-90-R) & 1.03 & $1.01-1.05$ \\
$\quad$ Physical stressors & & \\
Relationship between workers & 3.31 & $1.62-6.79$ \\
and supervisors & 2.47 & $1.06-5.79$ \\
Working spouse versus single & 1.02 & $0.27-3.84$ \\
$\quad$ Nonworking spouse versus single & 0.45 & $0.10-2.04$ \\
or working spouse & 1.01 & $1.00-1.03$ \\
Personality domain & 1.05 & $1.02-1.08$ \\
\hline Environment domain & & \\
\hline
\end{tabular}

a Michigan Alcoholism Screening Test.

b Center for Epidemiologic Studies Depression Scale.

- General Health Questionnaire.

¿ Global Severity Index of Symptom Check List.

dividual's odds of experiencing depression of at least moderate intensity increases by 7.3 for every unit change in the "relationship between workers and supervisors" variable, measured on a scale of $0-4$. Thus, an individual reporting an "extremely stressful" relationship with supervisors (score 4) had 29 times the odds of experiencing depression as did an individual reporting that his relationship with supervisors is "not at all stressful" (score 0). Also significant was the change in OR of 2.5 per unit increase in the "relationship between workers and supervisors" variable in a model with GSI as the dependent variable.

An increased risk of psychological distress, as measured by the GSI for those individuals experiencing physical stress, was indicated by the change 
in OR of 3.3 per unit increase in the "physical stress" variable. For the CES-D only, a reduced risk of depression was found for individuals having more years of employment (OR 0.66). For the GSI score only, individuals whose spouse did not work outside the home had a reduced risk of psychological distress (OR 0.45) compared with those fire fighters who were either not married or whose spouse did work outside the home.

\section{Discussion}

Results of this study suggest that over one-third of the fire fighters surveyed were experiencing significant psychological distress. The average CES-D score was 12.96 , and $33 \%$ of the fire fighters scored 16 or higher, a finding suggesting at least mild depression. For comparison, in a large survey of workmen between the ages of 25-74 years in the United States, 6.5\% had scores in this range (18). Men in a community sample (23) had an average CES-D score of 7.90. Men with acute depression had an average score of 37.14 , and "recovered depressives" had an average score of 18.58 .

On the SCL-90-R, the average GSI score of the fire fighters was 0.58 , and the median score was 0.46 . Utilizing Derogatis' recommended cut-off of the 90th percentile, we found that $41 \%$ of the fire fighters exhibited high distress (GSI >0.56). Using a less stringent cut-off of one standard deviation above the mean of the normative male sample from Derogatis' validation study of the SCL-90-R (14), Parkinson \& Bromet (24) found that $21 \%$ of the workers at the Three Mile Island nuclear plant exhibited high distress (average GSI 0.28) two years after the accident that occurred there. Green et al (25) surveyed 117 survivors of the Beverly Hills Supper Club fire in northern Kentucky one year after the disaster. The survivors' average GSI score on the SCL-90-R was 0.70 , placing them between the norms for "normals" and "psychiatric outpatients." In a study of 104 New York telephone employees self-selected for stress, Carrington (26) found an average GSI score of 0.74 . A comparison of study results with two-sample ttests showed that the mean GSI score of the 145 fire fighters in this survey was significantly higher than the normal nonpatient norms $(14)[\mathrm{t}=8.86$, degrees of freedom $(\mathrm{df})=1117, \mathrm{P}=0.0001)$ and the scores of the nuclear power plant workers in the study of Parkinson et al (24) $(\mathrm{t}=5.58, \mathrm{df}=247, \mathrm{P}<0.0001)$. The mean GSI score of the fire fighters was significantly lower than that of a population self-selected for stress (26) $(t=-2.44$, $\mathrm{df}=247, \mathrm{P}=0.015)$, but not significantly different from the mean score of a group of individuals who had experienced a traumatic incident one year earlier $(25)(\mathrm{t}=-1.95, \mathrm{df}=260$, $\mathrm{P}=0.094$ ).

Thirty-nine percent of the fire fighters had a score of two or higher on the GHQ, a finding suggestive of a high level of emotional distress. Comparison with previous studies utilizing the GHQ is difficult, since most of the surveys were not conducted in the United States and the questionnaire employed was usually a more comprehensive version of that used in this study. In a study of office workers in Hong Kong, which utilized the version of the GHQ incorporated into the present study, $25.5 \%$ of the male office workers scored two or higher (17).

Twenty-nine percent of the fire fighters surveyed had scores on the MAST suggestive of possible or probable current problems with alcohol use. Community studies in the United States have found that approximately $13 \%$ of the adult population has suffered from alcohol abuse or dependence at some time in their lives (27). At all ages, men are two to five times more likely to be "heavy drinkers" than women. In the original paper describing the MAST (19), of 103 individuals who were chosen to exclude "obvious alcoholics," including 67 white male blue-collar university employees and 36 white males randomly selected from patients visiting a university allergy clinic, $13(13 \%)$ of 103 had scores suggestive of possible or probable current problems with alcohol use. Thus the rate of possible or probable current problems with alcohol use among the fire fighters surveyed was high, particularly since the figure of $29 \%$ in this survey does not include fire fighters who had problems with alcohol use in the past, but who were abstinent at the time of the survey.

Healthier people tend to enter the work force and remain employed, while less healthy people are underrepresented in the working population, a phenomenon leading to a potential form of selection bias referred to as the "healthy worker effect" (28). It is conceivable that individuals with higher levels of psychological distress or use of alcohol dropped out of the work force prematurely or were never hired by the fire department; thus the levels of psychological morbidity reported for the fire fighters could potentially be deflated in comparison with those of community populations. In the absence of information on the psychological status of candidates who were rejected for the fire department and that of former fire fighters who left the department prior to usual retirement age, we cannot determine the extent to which the "healthy worker effect" may have operated in this study. The reduced risk of depression for individuals having a greater length of employment could have been due to seriously depressed individuals dropping out of the work force, but this hypothesis cannot be tested with the available data.

Given the cross-sectional nature of this study, it is not possible to determine the temporal sequence of relationships found in the regression analysis. The strongest finding of the logistic regression model was an increased risk of psychological distress, as measured by the SCL-90-R and CES-D, among those individuals reporting stressful worker-supervisor relationships. However, a study design utilizing self-reported measures of both stressors and mental health 
may lead to overcorrelations between environmental stress and health and well-being. Watson \& Pennebaker (29) have suggested that many stress-health correlations may be spuriously inflated because selfreport measures of both stress and health contain a significant component of "negative affectivity," a measure of subjective distress. The inherently subjective nature of psychological distress makes it difficult to circumvent this potential problem. However, future studies of psychological distress in fire fighters might be enhanced by the inclusion of standardized structured psychiatric interviews. The findings of this study would ideally be compared with those of a cohort matched for relevant variables such as age, gender, educational level, and physical work activity. Only careful clinical evaluation could determine whether fire fighters exhibiting high levels of psychological distress on symptom checklists suffer from actual diagnosable psychiatric disorders.

Despite these limitations, we feel that it is significant that the fire fighters surveyed scored poorly on all measures of mental health in comparison with the results of other published studies utilizing these instruments in community or occupational settings. The sources of work stress which may be contributing to these problems remain uncertain, as no relationship was found between measures of psychological distress and alcohol use and objectively measured work load, and none of the 10 most highly ranked work stressors entered into the regression model. These findings suggest that our model may lack critical occupational stress variables, or that factors other than work stress may be more predictive of psychological distress in the fire fighters studied.

\section{References}

1. Krantz L. Jobs rated almanac. New York, NY: Ballantine Books, 1988.

2. Polakoff PL. Attention should be given to limiting fire fighting hazards. Occup Health Saf 1984;53:55-6.

3. Barnard RG, Duncan HW. Heart rate and ECG responses of fire fighters. J Occup Med 1975;17:24750.

4. Kuorinka I, Korkonen O. Firefighters' reaction to alarm, an ECG and heart rate study. J Occup Med 1981;23:762-766.

5. Blimkie CJR, Rechnitzer PA, Cunningham DA. Heart rate and catecholamine responses of fire fighters to an alarm. Can J Appl Sports Sci 1977; 2:153-6.

6. Barnard RJ, Gardner GW, Diaco NV, Kattus AA. Near maximal ECG stress testing and coronary artery disease risk factor analysis in Los Angeles City fire fighters. J Occup Med 1975;17:693-5.

7. Dutton LM, Smolensky MH, Leach CS, Lorimor R, Hsi BP. Stress levels of ambulance paramedics and fire fighters. J Occup Med 1978;20:111-5.

8. Petrie K, Rotheram MJ. Insulators against stress: selfesteem and assertiveness. Psychol Rep 1982;50: $963-6$.
9. Clarke A, Innes JM. Sensation-seeking motivation and social-support moderators of the life stress/illness relationship: some contradictory and confirmatory evidence. Pers Individ Differ 1983;4:547-50.

10. Bieliauskas LA. Life events, 17-OCHS measures, and psychological defensiveness in relation to aid-seeking. J Hum Stress 1980;6:28-36.

11. Kalimo R, Lehtonen A, Daleva M, Kuorinka I. Psychological and biochemical strain in firemen's work. Scand J Work Environ Health 1980;6:179-187.

12. Markowitz, JS. Long-term psychological distress among chemically exposed firefighters. Behav Med $1989 ; 15: 75-83$.

13. Navarre RJ. Stress and fire fighters [dissertation]. Toledo, OH: University of Toledo, 1983.

14. Derogatis LR. SCL-90-R: administration, scoring and procedures II. Baltimore, MD: Clinical Psychometric Research, 1983.

15. Goldberg DP. The detection of psychiatric illness by questionnaire. London: Oxford University Press, 1972.

16. Vieweg BW, Hedlund JL. The general health questionnaire (GHQ): a comprehensive review. J Oper Psychiatry $1983 ; 14: 74-81$.

17. Lam TH, Ong SG, Wong CM, Lee PWH, Kleevens JWL. Mental health and work stress in office workers in Hong Kong. J Occup Med 1985;27:199-205.

18. Sayetta RB. Basic data on depressive symptomatology, United States, 1974-1975. Washington, DC: US Department of Health, Education and Welfare. (Vital and health statistics: series 11, data from the National Health Survey; no 216 (DHEW publication; (PHS) $80-1666)$.)

19. Selzer ML. The Michigan alcoholism screening test: the quest for a new diagnostic instrument. Am J Psychiatry $1971 ; 127: 1653-8$.

20. Hedlund JL, Vieweg VW. The Michigan alcoholism screening test (MAST): a comprehensive review. J Oper Psychiatry 1984;15:55-64.

21. Derogatis LR. The Derogatis stress profile (DSP), a summary report. Baltimore, MD: Clinical Psychometric Research, 1984.

22. Derogatis LR. The Derogatis stress profile (DSP): quantification of psychological stress. Adv Psychosom Med 1987;17:30-54.

23. Weissman MM, Sholomskas D, Pottenger M, Prusoff $\mathrm{BA}$, Locke BZ. Assessing depressive symptoms in five psychiatric populations: a validation study. Am J Epidemiol 1977;106:203-14.

24. Parkinson DK, Bromet EJ. Correlates of mental health in nuclear and coal-fired power plant workers. Scand J Work Environ Health 1983;9:341-5.

25. Green BL, Grace MC, Lindy JD, Titchener JL, Lindy JG. Levels of functional impairment following a civilian disaster: the Beverly Hills Supper Club fire. J Consult Clin Psychol 1983;51:573-80.

26. Carrington $\mathrm{P}$, Collings $\mathrm{GH}$, Benson $\mathrm{H}$, Robinson $\mathrm{H}$, Wood LW, Lehrer PM, et al. The use of meditationrelaxation techniques for the management of stress in a working population. J Occup Med 1980;22:221-31.

27. American Psychiatric Association. Diagnostic and statistical manual of mental disorders. 3rd ed. Washington, DC: American Psychiatric Association, 1987.

28. Rothman KJ. Modern epidemiology. Boston, MA: Little, Brown and Company, 1986.

29. Watson D, Pennebaker JW. Health complaints, stress and distress: exploring the central role of negative affectivity. Psychol Rev 1989;96:234-54.

Received for publication: 14 May 1992 